\title{
Expert System untuk Mendeteksi Penyakit Gigi Menggunakan Shell e2gLite dari Expertise2go
}

\author{
Tuesday Saka Gustaf ${ }^{1}$, Joan Santoso $^{2}$,Endang Setyati ${ }^{3}$ \\ 1,2,3 Program Studi Pasca Sarjana Teknologi Informasi \\ Sekolah Tinggi Teknik Surabaya
}

E-mail: ${ }^{1}$ sakagustaf@gmail.com ${ }^{*}{ }^{2}$ joan@istts.ac.id, ${ }^{3}$ endang@ @stts.edu

\begin{abstract}
Jumlah tenaga kerja kesehatan gigi di kalangan masyarakat dinilai kurang seimbang.Tujuan utama penelitian ini untuk mendeteksi penyakit pada gigi seseorang dengan menyediakan solusi berupa sistem pakar . Tahapan proses pada penelitian ini meliputi: Pembelajaran literatur mengenai Forward Chaining ,Certainly Factor dan software expertise2Go yaitu E2glite dan Pemahaman penerapan metode Certainly Factor, Menentukan batasan-batasan permasalahan dari penelitian mengenai penyakit pada gigi serta merumuskan serangkaian solusi-solusi berupa informasi untuk mengatasi permasalahan penyakit pada gigi.Nilai akurasi dihitung dari tingkat keberhasilan sistem melakukan pelacakan dan pemberian informasi yang tepat tentang diagnosa penyakit gigi dengan tingkat nilai akurasi sebesar $70 \%$. berdasarkan perbandingan data dan hasil kesimpulan sistem.
\end{abstract}

Kata kunci : sistem pakar,certainly factor , e2gLite, sistem pakar gigi .

The number of dental health workers in the community is considered to be less balanced. The main objective of this study is to detect diseases in a person's teeth by providing a solution in the form of an expert system.

The stages of the process in this study include: Learning literature on Forward Chaining, Certainly Factor and Expert2Go software, namely E2glite and understanding the application of the Certainly Factor method, Determining the boundaries of the problem of research on dental diseases and formulating a series of solutions in the form of information to overcome disease problems on the teeth.The accuracy value is calculated from the success rate of the system in tracking and providing accurate information about the diagnosis of dental disease with an accuracy value of $70 \%$. based on data comparison and system conclusions.

Keyword: expert system, certainly factor, e2gLite, dental system.

\section{Pendahuluan}

Perawatan medis pada gigi mengalami peningkatan pesat bila ditinjau tiap tahunnya. Sementara itu perbandingan antara jumlah pasien yang mengalami permasalahan pada gigi dengan jumlah tenaga kerja kesehatan gigi di kalangan masyarakat dinilai kurang seimbang.Sistem pakar yang dirancang diharapkan dapat menjadi semacam jembatan perantara ketika dalam sebuah keadaan tertentu seorang merasa kesulitan untuk menemui seorang ahli, khususnya seorang pakar kesehatan gigi.

Tujuan utama penelitian ini untuk mendeteksi penyakit pada gigi seseorang dengan menyediakan solusi berupa informasi-informasi untuk penanganan. Sistem nantinya dapat digunakan sebagai media pembelajaran bagi Mahasiswa Kedokteran Gigi serta media Promosi bagi klinik dokter gigi.

Tahapan proses pada penelitian ini meliputi:1) Pembelajaran literatur mengenai Forward Chaining ,Certainly Factor dan software expertise2Go yaitu E2glite 2) Pemahaman penerapan metode Certainly Factor, Menentukan batasan-batasan permasalahan dari penelitian mengenai penyakit pada gigi serta merumuskan serangkaian solusisolusi berupa informasi untuk mengatasi permasalahan penyakit pada gigi.

\section{BAHAN DAN METODE}

\section{A. Knowledge Base Management}

KBS atau Knowledge Base Management System pertama kali diperkenalkan pada tahun 1970 yang mana kemudian dikembangakan oleh beberapa peneliti yang pada tahun 1980 . Disiplin ilmu sistem pakar ini mampu berkembang pesat dari waktu ke waktu. Konsep knowledge base management system dirancang agar mampu untuk memecahkan permasalahan yang dihadapi pemakai dimana permasalahan cukup rumit dengan cara memberikan pertanyaan-pertanyaan yang mewakili aturan-aturan atau disebut dengan rules yang sudah ditetapkan sebelumnya. Proses tersebut diimplementasikan pada sebuah sistem komputer yang akhirnya dapat memberikan jawaban akan permasalahan yang sedang dihadapi oleh pemakai sistem (user) tersebut.

Knowledge Base Management System menurut penelitian yang dilakukan oleh beberapa peneliti antara lain yaitu Mahmoud J. Abu Ghali, Mohammed N. Mukhaimer, Mohammed K. Abu Yousef, Samy S. Abu Naser (Expert System for Problems of Teeth and Gums) berpendapat bahwa knowledge base management system merupakan salah satu bentuk implementasi dunia artificial intelegence.

Pada penelitian ini mendefinisikan istilah knowledge base management system sebagai sebuah sistem komputer yang mempunyai kemampuan yang dapat mengambil sebuah keputusan. Di dalam sistem pakar tersebut diberikan sebuah proses pembelajaran (learning) yang terkait dengan aturanaturan (rules) sistem pakar.Aturan-aturan tersebut merupakan pengetahuan hasil wawancara dari seorang pakar.Sehingga memudahkan pemakai dalam memecahkan masalah yang sedang dihadapi dengan kecepetan dimana tidak terhalang oleh faktor waktu dan jarak.Serta memberikan solusi serta jawaban yang terukur dan teruji sebelumnya.

\section{B. Certainty Factor}

Metode Certainty Factor merupakan perpaduan asumsi 
kepercayaan dan ketidakpercayaan terhadap data yang disajikan dimana melakukan perbandingan antara asumsi sang pakar (expert system) dan asumsi pemakai (user) . ketika terjadi perpaduan asumsi tersebut diharapkan penelitian ini memberikan pemecahan yang valid terhadap pemasalahan yang ada.Cara kerja penelitian ini adalah expert system akan menampilkan berbagai varian penyakit yang sesuai dengan gejala - gejala yang di berikan oleh pemakai,berupa jawaban atas pertanyaan - pertanyaan yang ditampilkan oleh sistem dimana masing masing pertanyaan juga diwajibkan untuk menjawab tingkat keyakinan user terhadap jawaban tersebut.karakter certainty factor dianggap cocok ketika memecahkan masalah yang mengandung ketidak pastian.

Ketika user diminta utuk memasukkan nilai keyakinan atas jawabannya maka akan membentuk suatu kombinasi nilai yang akan dihitung menggunakan metode certainty factor.Hasil dari penghitungan akan membentuk suatu ukuran kepastian terhadap fakta dan aturan yang sebelumnya telah ditampilkan dan di rumuskan dalam bentuk basis pengetahuan (knowledge base).

Beberapa peneliti bernama Shotliffe dan Buchanan ditahun 1975 membuat suatu rumusan mengenai ketidakpastian pemikiran atau inexact reasoning yang sering terjadi terhadap seorang pakar.

Sering dalam banyak kasus para pakar dalam penelitian ini adalah dokter gigi dimana sesuai kaitannya dengan obyek penelitian yaitu penyakit gigi selalu memberikan informasi terhadap pasiennya dengan kata - kata "kemungkinan" karena ketidakmutlakan akan analisa yang sedang diberikannya.

Metode certainty factor merupakan metode yang digunakan untuk memberikan informasi keyakinan sang pakar akan penyakit gigi yang sedang didiagnosa. Dua model yang selalu digunakan untuk mendapatkan tingkat keyakinan (CF) menurut sutojo tahun 2011 terdiri atas :

E.H. Shortliffe dan B. G. Buchanan merumuskan Metode 'Net Belief'. Rumusan tersebut menghasilkan persamaan:

$$
C F(\text { Rule yang dibuat })=M B(H, E)-M D(H, E)
$$

\section{Keterangan :}

$\mathrm{CF}($ Rule yang dibuat ) : Faktor kepastian

$\mathrm{MB}(\mathrm{H}, \mathrm{E})$ : Jika evidence $\mathrm{E}$ (bernilai 0 hingga 1) maka simbol tersebut berarti Measure of Belief terhadap hipotesis $\mathrm{H}$

$\mathrm{MD}(\mathrm{H}, \mathrm{E})$ : Jika diberikan evidence $\mathrm{E}$ (bernilai 0 hingga

1)

maka simbol tersebut berarti Measure of Disbelief terhadap evidence $\mathrm{H}$

1) Wawancara terhadap pakar dipakai sebagai bahan referensi dalam mendapatkan informasi.Dimana informasi yang didapat diolah dalam bentuk interpretasi,mendefinisikan hasil jawaban dalam bentuk nilai CF sehingga dapat di hitung dengan persamaan certainty factor.
TABEL NILAI CERTAINTY FACTOR (RULE)

DALAM BENTUK NILAI

\begin{tabular}{|l|c|}
\hline \multicolumn{1}{|c|}{ JAWABAN } & NILAI \\
\hline Pasti Tidak & 0 \\
\hline Tidak tahu & 0.2 \\
\hline Kemungkinan kecil & 0.4 \\
\hline Cukup yakin & 0.6 \\
\hline Yakin & 0.8 \\
\hline Sangat yakin & 1 \\
\hline
\end{tabular}

\section{Menghitung CF Pararel}

Bila beberapa premis dari aturan yang ada di rumuskan pada metode certainty factor maka disebut CF paralel.Pada certainty factor rumus untuk masing-masing operator dapat dilihat pada persamaan :

$C F$ (a dan b) maka min $(C F(a), C F(b))$

$C F(a$ atau b) maka max $(C F(a), C F(b))$

CF (tidak a) maka $\sim C F(a)$

\section{Keterangan:}

$\mathrm{CF}(\mathrm{a}), \mathrm{CF}(\mathrm{b})$ merupakan nilai $\mathrm{CF}$ pararel terhadap premis yang disajikan dalam bentuk knowledge base.

\section{Menghitung CF Sekuensial}

Dalam menghitung CF Sekuensial pada sebuah rule di hitung dengan menggunakan rumus :

$$
\mathrm{CF}(\mathrm{H}, \mathrm{e})=\mathrm{CF}(\mathrm{E}, \mathrm{e}) * \mathrm{CF}(\mathrm{H}, \mathrm{E})
$$

Keterangan :

CF (E,e):Certainty Factor evidence E bergantung terhadap evidence $e$

$\mathrm{CF}(\mathrm{H}, \mathrm{e})$ :Certainty Factor hipotesis dimana evidence sudah diketahui terlebih dahulu dengan syarat $\mathrm{CF}(\mathrm{E}, \mathrm{e})=1$.

$\mathrm{CF}(\mathrm{H}, \mathrm{E})$ :Certainty Factor yang bergantung kepada evidence $e$

Pada rumus $\mathrm{CF}$ Sekuensial didapatkan dari hasil menghitung CF paralel dari premis - premis yang berada pada satu aturan yang sebelumnya telah diberikan oleh pakar. Berikut rumus dari CF sekuensial:

$$
C F(a, b)=C F(a) *(C F(b))
$$

Keterangan :

$$
\begin{array}{ll}
\mathrm{CF}(\mathrm{a}, \mathrm{b}) & : \mathrm{CF} \text { pararel } \\
\mathrm{CF}(\mathrm{a}) & : \text { CF sekuensial yang dapat dari premis } \\
\mathrm{CF}(\mathrm{b}) & \text { : Nilai CF yang didapatkan dari informasi } \\
& \text { pakar }
\end{array}
$$

\section{E. Menghitung CF Gabungan}

Certainty Factor gabungan didapatkan dari nilai CF paralel yang dimiliki oleh masing masing aturan pada premis tersebut.Hal ini terjadi pada kasus dimana hasil konklusi 
menunjukkan penyakit yang sama tetapi dengan gejala yang berbeda -beda.Contoh kasus pertama pada penyakit Q1 memiliki gejala R1,R2,R3 dan sedangkan kasus kedua dimana pada gejala S1,S2 dan S3 malah menghasilkan konklusi berupa penyakit yang sama yaitu Q1,dari pernyataan diatas bisa diambil persamaan $\mathrm{CF} 1(\mathrm{Q} 1, \mathrm{R})$ dan $\mathrm{CF} 2(\mathrm{Q} 1, \mathrm{~S})$,sehingga bisa diambil kesimpulan bahwa nilai certainty factor gabungan merupakan sebuah konklusi akhir.Berikut persamaan yang menggambarkan kasus pada CF Gabungan :

$$
C F(C F 1, C F 2)=\left\{\begin{array}{c}
C F 1+C F 2(1-C F 1) \text { jika } C F 1>0 \text { dan } C F \\
\frac{C F 1+C F 2}{1-\min [|C F 1|,|C F 2|]} j i k a C F 1>0 \text { dan } C F 2 \\
C F 1+C F 2 \times(1+C F 1) \text { jika } C F 1>0 \text { dan } C
\end{array}\right.
$$

Peran aktif seorang pakar merupakan domain knowledge yang dibutuhkan oleh sistem pakar namun pada kenyataannya hal ini memerlukan waktu dan tenaga yang harus dimaksimalkan agar mendapatkan hasil yang maksimal.Ketika dilakukan proses perhitungan $\mathrm{CF}$ gabungan tiap gejala diberikan nilai certainty factor oleh pakar dan pasien sehingga hasil akhirnya akan mendapatkan diagnosis yang tepat.

\section{F. Penerapan Certainty Factor}

Untuk mendapatkan nilai $\mathrm{P}(\mathrm{H})$ yang merupakan data penyakit dan gejala $(\mathrm{H})$ peneliti menggunakan data dari rekam medik yang didapat dari rumah sakit.Data diambil dari penderita penyakit gigi berjumlah 600 orang, misal data ginggivitis menghasilkan nilai 0,125 didapatkan dari 25 penderita ginggivitis di bandingkan dengan data awal yaitu 600 pasien.

$P$ [Ginggivitis] $=25 / 600=0,041$

$P[$ Ludwig anggina $]=20 / 600=0,033$

$P$ [tak terinci] $=145 / 600=0,241$

Berikut ini adalah data mengenai jumlah pasien yang mengalami permasalahan terhadap giginya yang dapat diuraikan sebagai berikut :

Sedangkan nilai probabilitas $\mathrm{P}[\mathrm{H}]$ misal $\mathrm{P}$ [Ginggivitis] nantinya akan dimasukkan dalam persamaan yang diolah untuk dikalikan dengan nilai Measure of Believe (MB) dan Measure of Disbelieve (MD) setiap gejala pada penyakit yang akan dituju untuk mendapatkan tingkat kepastian penyakit terhadap gejala tersebut.

Berikut variabel yang akan akan digunakan :

$\mathrm{H}$ : Ginggivitis

G1 : Gusi bengkak

G3 : Rasa ngilu ketika gusi tersentuh

G7 : Gigi nyeri

G10 : Mulut mengeluarkan bau tidak sedap

G13 : Gigi terasa goyang

Maka nilai probabilitas terhadap gejalanya adalah nilai ini didapatkan dari inputan user misal inputan user terhadap gejala:

$P($ Ginggivitis $\mid G 1)=0,6$

$P($ Ginggivitis $\mid G 3)=0,8$

$P($ Ginggivitis $\mid G 7)=0,4$

\section{$P($ Ginggivitis $\mid G 10)=1$}

$P($ Ginggivitis $\mid G 13)=1$

Selanjutnya sistem menghitung nilai probabilitas penyakit erosi gigi terhadap gejalanya dibandingkan dengan jumlah tipe penyakit gigi dan gejala yang telah diinputkan oleh pemakai sistem. Nilai tingkat keyakinan bahwa penyakit gigi berupa ginggivitis diindikasikan dengan penghitungan probabilitas penyakit menggunakan rumus diatas.

TABEL GEJALA PENYAKIT GIGI

\begin{tabular}{|c|c|}
\hline No & Gejala-Gejala Penyakit Gigi \\
\hline 1 & Gusi bengkak \\
\hline 2 & Gusi berdarah \\
\hline 3 & Gusi sakit jika disentuh \\
\hline 4 & Radang gusi \\
\hline 5 & Gusi mengkilat \\
\hline 6 & Gigi berlubang \\
\hline 7 & Gigi nyeri \\
\hline 8 & Gigi ngilu \\
\hline 9 & Gigi patah \\
\hline 10 & Mulut mengeluarkan bau tidak sedap \\
\hline 11 & $\begin{array}{l}\text { Terasa ngilu pada gigi saat makan atau minum panas dan } \\
\text { dingin }\end{array}$ \\
\hline 12 & Terasa pahit pada mulut pasien \\
\hline 13 & Terjadi penurunan kekuatan gigi merasa gigi goyang \\
\hline 14 & Terasa nyeri saat menggigit objek \\
\hline 15 & Gusi terdapat benjolan \\
\hline 16 & Bagian persendian rahang mengalami rasa sakit \\
\hline 17 & Bagian telinga terasa sakit \\
\hline 18 & Menelan makanan teasa sulit \\
\hline 19 & Bagian wajah mengalami rasa sakit \\
\hline 20 & Terdengar suara click ketika proses mengunyah makanan \\
\hline 21 & Mengalami kesulitan membuka dan menutup rahang \\
\hline 22 & Bagian kepala mengalami rasa sakit \\
\hline 23 & Ketika menggigit merasa tidak nyaman \\
\hline 24 & Bagian leher mengalami rasa sakit dan bengkak \\
\hline 25 & Terdapat tanda merah di bagian leher \\
\hline 26 & Mengalami demam \\
\hline 27 & Tubuh terasa lemah \\
\hline 28 & Mengalami rasa lesu pada tubuh \\
\hline 29 & Rasa capek yang berlebihan \\
\hline 30 & Mengalami rasa linglung pada saat berpikir \\
\hline 31 & Mengalami kesulitan nafas dan terjadi perubahan mental \\
\hline 32 & Bagian gusi terdapat warna merah terang dankeunguan \\
\hline 33 & Pada bagian gusi marasa tebal saat terjadi sentuhan \\
\hline 34 & $\begin{array}{l}\text { Pada bagian gusi terdorong maju sehingga gigi terlihat } \\
\text { panjang }\end{array}$ \\
\hline 35 & Terdapat jarak diantara satu gigi dan yang lain \\
\hline 36 & Mengalami rasa yang tidak enak pada bagian mulut \\
\hline
\end{tabular}




\begin{tabular}{|l|l|}
\hline No & \multicolumn{1}{|c|}{ Gejala-Gejala Penyakit Gigi } \\
\hline 37 & Mengalami gigi gigi yang tiba tiba tanggal dengan sendirinya \\
\hline 38 & Barisan gigi mengalami perubahan yang cukup signifikan \\
\hline 39 & Mengalami kekeringan pada bagian mulut \\
\hline 40 & Seperti terdapat lapisan pada bagian lidah \\
\hline
\end{tabular}

Penelitan ini peneliti mengambil data penyakit gigi dari rumah sakit di Surabaya. Data-data ini didapatkan dari hasil wawancara dengan nara sumber yaitu beberapa Dokter senior yang sedang bertugas di rumah sakit. Berikut ini disajkan data-data penyakit gigi antara lain yaitu :

TABLE

KODE PENYAKIT GIGI

\begin{tabular}{|l|l|}
\hline Kode & \multicolumn{1}{|c|}{ KeTERANGAN PENYAKIT } \\
\hline P1 & Erosi Gigi \\
\hline P2 & Ginggivitis \\
\hline P3 & Pulpitis \\
\hline P4 & Abses Gigi \\
\hline P5 & Periodon-titis \\
\hline P6 & Karies Gigi \\
\hline P7 & Halitosis \\
\hline P8 & Sindrom Gigi Retak \\
\hline P9 & Temporomandibular Joint \\
\hline P10 & Ludwig angina \\
\hline
\end{tabular}

RULEs Untuk Metode Forward ChaINING PENYAKIT Gigi

\begin{tabular}{|l|c|}
\hline \multicolumn{1}{|c|}{ RULE } & KODE \\
\hline $\begin{array}{l}\text { If G1 and G3 and G7 and G10 and } \\
\text { G13 }\end{array}$ & P1 \\
\hline $\begin{array}{l}\text { If G1 and G2 and G3 and G4 and G5 } \\
\text { and G7 and G10 }\end{array}$ & P2 \\
\hline If G1 and G7 and G10 and G11 & P3 \\
\hline $\begin{array}{l}\text { If G1 and G7 and G10 and G11 and } \\
\text { G12 }\end{array}$ & P4 \\
\hline $\begin{array}{l}\text { If G1 and G7 and G10 and G32 and } \\
\text { G33 and G34 and G35 and G36 and }\end{array}$ & P5 \\
\hline If G6 and G7 and G9 and G10 & P6 \\
\hline If G10 and G36 and G39 and G40 & P7 \\
\hline If G8 and G14 and G15 & P8 \\
\hline $\begin{array}{l}\text { If G16 and G17 and G18 and G19 and } \\
\text { G20 and G21 and G22 and G23 }\end{array}$ & P9 \\
\hline $\begin{array}{l}\text { If G24 and G25 and G26 and G27 and } \\
\text { G28 and G29 and G30 and G31 }\end{array}$ & P10 \\
\hline
\end{tabular}

\section{G. Workflow Sistem Pakar}

Proses keseluruhan dari analisa dari keseluruhan sistem pakar nampak pada gambar di bawah ini.dalam perancangan tersebut terbagi menjadi 3 bagian utama yaitu blok pasien /operator, blok sistem dan blok dokter selaku pakar.

Masing masing blok berperan terhadap sistem sehingga membentuk aliran data yang terintegrasi.User dalam system ini bisa operator rumah sakit, mahasiswa kedokteran atau pasien klinik . User menginput gejala yang dialami, maka secara otomatis biodata diambil dari data profil pasien pada system informasi rumah sakit gigi ,setelah diolah oleh system expert maka hasil rekomendasi diagnosis ditampilkan untuk melakukan verifikasi dan koreksi oleh pakar dalam hal ini adalah dokter yang telah terpilih .Menampilkan hasil diagnosis pada user sesuai dengan olahan hasil dari expert system.

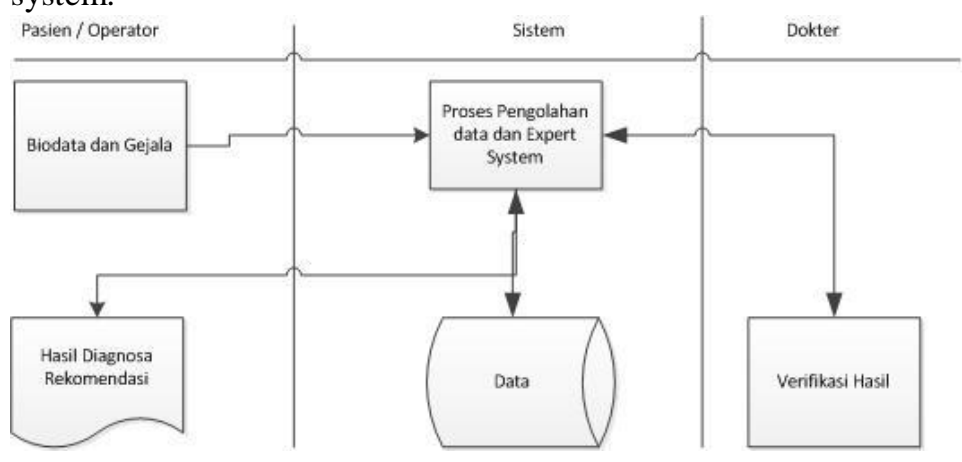

\section{H. Pseudocode Konsultasi Aplikasi Sistem Pakar}

Tampilan Utama

Do Pilih Pilih = "Login" lakukan modul menu login konsultasi

Pilih = "Konsultasi" lakukan modul menu konsultasi

Pilih = "Cari Data Pasien" lakukan modul cari data pasien

Tampilkan Submenu Data Konsultasi

Pilih =" Konsultasi" masukkan modul menu sub Data

Konsultasi pada tampilan menu User

Do Pilihan

Pilih =" Proses Konsultasi" lakukan modul Proses Konsultasi pada Data Konsultasi

Pilih =" Hitung Hasil" lakukan modul Hitung Hasil

Certainly factor pada Data Konsultasi

Else if

pilih =" Solusi " lakukan modul Solusi pada Data

Konsultasi hasil dari proses perhitungan hasil

Then jawab =" Solusi berhasil"

End if.

\section{HASIL DAN PEMBAHASAN}

Berdasarkan hasil pembahasan dan dokumentasi dapat diambil kesimpulan yaitu :

1) Sistem pakar untuk mendiagnosa penyakit gigi berbasis web menggunakan certainly factor berhasil membantu seorang yang bukan pakar untuk mengambil kesimpulan penyakit yang diderita berdasarkan gejala gejala yang diberikan.

2) Sistem Pakar gigi berhasil dibangun dengan menerapkan metode Certainty Factor (CF) sebagai metode perhitungan dan hasil diagnosa penyakit terbukti akurat.

Kedepannya pengembangan Sistem Pakar Penyakit Gigi ini yaitu dengan melengkapi rule-rule untuk penyakit-penyakit 
gigi yang lain, dimana jumlahnya bisa mencapai puluhan bahkan ratusan penyakit, melengkapi sistem dengan data gambar gigi dengan lebih lengkap sehingga lebih memudahkan dan meyakinkan pemakai bahwa hasil kesimpulan akurat.

\section{KESIMPULAN}

Dari pengujian pada penelitian yang telah dilakukan, dapat dihasilkan kesimpulan bahwa sistem pakar ini dapat membantu dokter gigi muda untuk melakukan diagnosa.sehingga mereka lebih pakar dalam mengalami kasus yang nantinya akan dihadapi dan mengurangi kemungkinan kesalahan diagnosa.

Penambahan penangan atau terapi gigi bisa ditambahkan agar bisa memberikan edukasi pada para dokter muda agar tidak ragu atau tidak melakukan kesalahan dalam menentukan terapi yang akan dilakukan sehingga tidak terjadi masalah pada pasien akibat kesalahan penanganan terapi pada pasien.

\section{REFERENSI}

[1] Whisnu Ulinnuha Setiabudi, Endang Sugiharti, Florentina Yuni Arini(Expert System Diagnosis Dental Disease Using Certainty Factor Method )

[2] Mahmoud J. Abu Ghali, Mohammed N. Mukhaimer, Mohammed K. Abu Yousef, Samy S. Abu Naser (Expert System for Problems of Teeth and Gums)

[3] Sulindawaty, Muhammad Zarlis, Zakarias Situmorang, Hengki Tamando Sihotang(Expert System Diagnosis Corn Pests And Diseases Using Certainty Factor Method)

[4] Mardi Turnip, Sistem Pakar Diagnosa Penyakit THT Menggunakan Metode Backward Chaining. Riau Journal Of Computer Science Vol.1/No.1/2015:1- 8

[5] C P C Munaiseche*, D R Kaparang and P T D Rompas (An Expert System for Diagnosing Eye Diseases using Forward Chaining Method)

[6] Aryu Hanifah Aji, M. Tanzil Furqon, Agus Wahyu Widodo (Sistem Pakar Diagnosa Penyakit Ibu Hamil Menggunakan Metode Certainty Factor $(\mathrm{CF})$ )

[7] Rina Miranda1, Nelly Astuti Hasibuan, Pristiwanto, Mesran (SISTEM PAKAR MENDIAGNOSA PENYAKIT JAMUR AKAR PUTIH (RIQIDOPORUS LIGNOSUS) PADA TANAMAN KARET (HAVEA BRASILIENSIS) DENGAN METODE CERTAINTY FACTOR

[8] Tutur Larasati, M. Rudyanto Arief ( SISTEM PAKAR DIAGNOSA AWAL PENYAKIT KULIT KUCING BERBASIS WEB MENGGUNAKAN METODE CERTAINTY FACTOR )

[9] T Sutojo, S Si, M Kom,2011,(Kecerdasan Buatan, Yogyakarta) 